\title{
SEJARAH PENDIDIKAN ISLAM DI MINANGKABAU
}

\author{
Saharman \\ Universitas Islam Negeri Imam Bonjol Padang \\ Email: saharman@uinib.ac.id
}

\begin{abstract}
This study aims to describe the development of Islamic education in Minangkabau. Library studies are used in collecting data and analyzing data qualitatively. The development of Islamic Education Institutions in the archipelago shows the influence of the development of Islamic education in the Middle East, especially Mecca and Cairo, although in detail there are differences in understanding. This influence was brought by natives who were initially to perform the pilgrimage, but then most of them settled there a few years to seek knowledge. Not much different from Minangkabau, at the end of the 17th century, it was influenced by Aceh by Syekh Burhanuddin Ulakan who went to study religious knowledge for several years, and then after returning home, established a mosque in the form of an educational institution with a halakah system. Furthermore, in the 20th century the madrasa was established as a sign of the beginning of the renewal of Islamic education by the best sons of Minangkabau by following the system carried out by previous ulama scholars, so that Islamic Education Institutions in Minangkabau continued to develop into universities. It is concluded that Syeh Burhanuddin has influence in the history of the development of Islamic education in Minangkabau.
\end{abstract}

Key Words: History, Islamic education, 'ulama

\section{PENDAHULUAN}

Kegiatan pendidikan Islam di Minangkabau lahir dan tumbuh serta berkembang bersamaan dengan masuk dan berkembangnya Islam di Minangkabau. Sesungguhnya kegiatan pendidikan Islam tersebut merupakan pengalaman dan pengetahuan yang penting bagi kelangsungan perkembangan Islam dan umat Islam, baik secara kuantitas maupun kualitas.

Menurut sebagian ahli sejarah, Islam masuk ke Minangkabau kira-abad ke $7 \mathrm{M}$ dan ada pula yang berpendapat tahun 1250 M. Ulama yang termasyhur sampai sekarang sebagai penyebar Islam ke Minangkabau adalah Syekh Burhanuddin yang dilahirkan di Sintuk Pariaman tahun 1066 H/ $1646 \mathrm{M}$ dan wafat tahun $1111 \mathrm{H} /$ 1691 M. Dia mengajarkan agama Islam dan membuka madrasah (surau) tempat pendidikan dan pengajaran agama Islam. Menurut Prof. H. Mahmud Yunus, Syekh inilah yang pertama kali mendirikan madrasah untuk menyiarkan pendidikan dan pengajaran Islam di Minangkabau dengan sistem yang lebih teratur sesuai dengan sistem pendidikan dan pengajaran Islam yang digunakan gurunya, Syekh Abdul Rauf di Aceh (Enung K. Rukiati, 2004).

Pada masa sebelum tahun 1900, sistem pendidikan di Minangkabau dinamai sistem halakah. Sistem lama itu dilakukan dengan pengajian Al-Qur'an sebagai sistem pendidikan Islam pertama. Sistem ini meliputi cara mengajarkan huruf Al-Qur'an (hijaiyah), yaitu dengan cara mengajarkan nama-nama huruf menurut tertib Qidah Bagdadiyah, kemudian titik huruf, macam-macam 
baris dan membaca juz Amma, selanjutnya mushaf Al-Qur'an. Cara mengajarkan ibadah bermula dari bersuci, wudhu, lalu shalat. Cara mengajarkan akhlak melalui cara menceritakan nabinabi dan orang shaleh, serta suri teladan dari guru agamanya. Cara mengajarkan iman, dengan cara mengajarkan keimanan. Pengajian kitab yang diajarkan bila anak telah mampu membaca AlQur'an, yaitu dengan mempelajari kitab nahu, sharaf, ilmu fikih, ilmu tafsir dan lain-lain.

Artikel ini bertujuan untuk menguraikan dan menganalisis berbagai hal yang berhubungan dengan dinamika pendidikan Islam di Minangkabau terutama yang berkaitan dengan perkembangan madrasah, terkait dengan unsur-unsur, fungsi, prinsip-prinsip, dan ciri-ciri madrasah.

\section{METODE PENELITIAN}

Untuk memaparkan sejarah Pendidikan Islam di Minangkabau dilakukan dengan mengumpulkan data dari pendapat para pakar Sejarah Pendidikan Islam baik lokal maupun bersifat nasional lewat buku atau hasil penelitian lapangan. Untuk melengkapi data tersebut juga DIlakukan studi dokumentasi di UIN Imam Bonjol Padang terutama di kantor Kopertais Wiulayah VI Sumatera Barat.

\section{HASIL PENELITIAN DAN PEMBAHASAN}

\section{Periodesasi Pendidikan Islam di Minangkabau}

Pendidikan Islam menjadi tolak ukur, bagaimana Islam dan umatnya telah memainkan peranan dalam berbagai aspek sosial, politik, budaya. Oleh karena itu, untuk melacak sejarah pendidikan Islam di Minangkabau dengan periodesasinya, baik dalam pemikiran, isi, maupun pertumbuhan oraganisasi dan kelembagaannya tidak mungkin dilepaskan dari fase-fase yang dilaluinya.

Fase-fase tersebut secara periodisasi dapat dibagi menjadi: 1. Periode masuknya Islam ke Minangkabau; 2. Periode pengembangan dengan melalui proses adaptasi; 3. Periode kekuasaan kerajaan-kerajaan di Minangkabau (proses politik); 4. Periode penjajahan Belanda (1619 - 1942); 5. Periode penjajahan Jepang (1942 - 1945); 6. Periode kemerdekaan I Orde lama (1945 - 1965); 7. Periode kemerdekaan II Orde Baru/Pembangunan (1966- 1998); 8. Periode reformasi (1998- sekarang).

Lembaga Pendidikan Islam di Minangkabau, dalam pandangan sejarah senantiasa berkembang mengikuti perkembangan sejarah bangsa Indonesia. Pada masa awal perkembangan Islam di Minangkabau telah berkembang sistem pendidikan yang dikenal dengan nama Surau. Sistem ini terdiri dari 3 unsur yakni Buya/Ulama yang berperan sebagai guru/tutor, murid dan asrama sebagai tempat menginap para murid.

Setelah Islam semakin berkembang, dan banyak orang-orang Islam Minangkabau yang belajar ke Timur Tengah, serta banyaknya orang-orang yang pergi haji, bermukim di tanah Suci, sekembalinya ke Tanah Air mereka membawa pikiran-pikiran baru dan mengadakan pembaharuan dan perubahan sistem dari surau menjadi madrasah, dengan sistem madrasah ini merubah cara belajar khlaqah menjadi 
klasikal. Demikian pula dari segi materi pelajaran, sistem madrasah semakin lebih terarah dan sempurna. Tidak hanya mengajarkan pengetahuan agama, melainkan juga mengajarkan pengetahuan umum.

Sebagai salah satu lembaga pendidikan Islam tertua di Minangkabau, madrasah telah melalui berbagai peradaban hingga sampai pada zaman modern di abad 21 saat ini. Sebagai lembaga yang bergerak dalam hal keilmuan khususnya ilmu agama, madrasah telah menunjukkan eksistensinya sebagai lembaga yang tetap kokoh dalam berpegang teguh pada nilainilai keagamaan yang bersumber pada AlQur'an, Hadits, dan Qoul Ulama (yang terepresentasikan dalam kitab kuning). Oleh karena itu madrasah memiliki nilainilai yang tidak sama dengan lembaga pendidikan lainnya.

\section{Ciri Ciri Lembaga Pendidikan}

Lembaga pendidikan Islam di Minangkabau pada awalnya terdiri dari Madrasah/ Gedung, masjid, murid, kitab kuning, dan buya merupakan lima dasar dari tradisi madrasah. Ini berarti bahwa suatu lembaga pendidikan keagamaan yang telah berkembang harus memiliki kelima elemen tersebut, dengan ciri ciri sebagai berikut: Pertama, Madrasah/Gedung. Pada dasarnya adalah sebuah asrama pendidikan Islam tradisional dimana para murid tinggal bersama dan belajar bersama dibawah asuhan seorang buya. Asrama tersebut biasanya berada dalam lingkungan kompleks madrasah; Kedua, Masjid. Merupakan elemen yang tak dapat dipisahkan dengan pesantren. Masjid juga dianggap sebagai tempat yang tepat untuk mendidik para murid dalam beribadah dan memperdalam ilmu agama.

Ketiga, Murid. Merupakan elemen penting dalam kelangsungan pesantren. Biasanya santri terbagi atas santri mukim (santri yang menetap di asrama pesantren) dan santri kalong (santri yang berasal dari desa di tempat pesantren berada, mereka tidak menetap di asrama). Murid di Minangkabau sebelum era orde baru tidak mengenal santri, dan pesantren tetapi lebih populer dengan sebutan murid, karena santri itu baru dikenal di Sumatera Barat setelah zaman Suharto. Ini merupakan salah satu bentuk perobahan pengaruh dari Jawa yang datang ke Sumatera Barat dan langsung dipakai tanpa mempertimbangkan dari mana asal usul nama santri dan tanpa menganalisa perbedaan nama santri dengan murid.

Keempat, Kitab Kuning/Kitab Klasik. Kitab-kitab yang diajarkan di pesantren tergolong kedalam: Nahwu dan Sharaf, Fiqh, Ushul Fiqh, Hadits, Tafsir, Tauhid, Tasawuf dan Etika, Tarikh dan juga Balaghah. Kitab kitab ini adalah materi pokok dalam kurikulum pesantren.

Kelima, Buya/Syekh. Dalam kosakata Jawa disebut kiai, gelar buya/Syekh dipakai untuk tiga jenis yang berbeda. Sebagai gelar kehormatan bagi barangbarang yang dianggap keramat, misalnya "Syekh Sulaiman ar-Rasuli", sebutan kehormatan terhadap pimpinan Madrasah Tarbiyah Islamiyah Candung Bukittinggi. Sebagai gelar kehormatan untuk orang tua pada umumnya. Umumnya gelar buya dilekatkan pada seorang ahli agama Islam yang memiliki atau menjadi pemimpin madrasah, dan mengajar kitab-kitab klasik. Selain itu gelar buya juga dipakai untuk sebutan orang yang alim (orang 
yang sangat luas pengetahuan keagamaannya).

\section{Dinamika Pendidikan Islam}

Lembaga Pendidikan Islam/ Madrasah sebagai lembaga sosial, telah menyelenggarakan pendidikan formal baik sekolah agama (madrasah) ataupun sekolah umum. Disamping itu, madrasah juga menyelenggarakan pendidikan non formal berupa madrasah diniyah yang mengajarkan materi keagamaan, selain itu juga mengadakan forum kajian keislaman yang terkonsentrasi pada kajian kitab kuning dengan berbagai disiplin ilmu agama yang telah disebutkan diatas.

Dalam pelaksanaan penyelenggaraan pendidikan diatas, madrasah mampu menampilkan eksistensinya sebagai lembaga solidaritas sosial dengan menampung santri dari berbagai lapisan masyarakat muslim dan memberikan pelayanan yang sama kepada mereka, tanpa membedakan latar belakang ataupun tingkat sosial ekonomi mereka.

Disamping itu, kharisma seorang ulama/buya madrasah juga mampu menjadi figur yang cukup efektif dalam perannya sebagai perekat hubungan dan pengayom masyarakat, baik pada tingkat lokal sampai nasional. Para ulama juga sering mengadakan wirid yang melibatkan berbagai lapisan masyarakat, baik yang diadakan atas inisiatif madrasah juga seringkali berasal dari inisiatif masyarakat.

Dengan berbagai peran potensial yang dimainkan madrasah, dapat dikemukakan bahwa madrasah memiliki tingkat integritas yang tinggi dengan masyarakat sekitarnya, sekaligus menjadi rujukan atas berbagai persoalan masyarakat. Fungsi-fungsi ini akan tetap terpelihara dan efektif manakala para pimpinan madrasah dapat menjaga independensinya dari berbagai intervensi di luar madrasah.

Sejarah telah memberikan informasi bahwa Minangkabau merupakan cikal bakal tumbuh dan berkembanganya pendidikan Islam. Partisipasi ulama cukup besar pengaruhnya dalam mencerdaskan kehidupan masyarakat serta memperjuangkan kemerdekaan baik pada tingkat regional maupun nasional.

Di antara para pembaharu pendidikan Islam di Minangkabau adalah H. Muh. Taib Umar (1874-1920), Syekh H. Abdul Karim Amrullah (1879-1945), Syekh H. Ibrahim Musa (1884), Syekh Abdullah Ahmad (1878-1933), Syekh M. Jamil Jambek (1860-1947), Syekh H. Abbas Abdullah (1883-1957), Zaenuddin Labai el Yunusi (1890-1924). Kemudian juga berdiri Madrasah Tarbiyah Islamiyah pada tanggal 5 Mei tahun 1928 yang dipimpin oleh Syekh Sulaiman ar-Rasuli, Syekh Muhammad Jamil Jaho Padang Panjang dan Syekh Abdul Wahid asShalihi di Tabek Gadang Kabupaten 50 Kota. Merekalah yang berjasa besar terhadap kemajuan pendidikan Islam di Minangkabau yang sampai sekarang masih terus ditumbuhkembangkan.

Adapun sistem baru yang digunakan dalam pendidikan dan pengajaran di Minangkabau dimulai tahun 1900. Pada tahun 1909-1930, lahirlah madrasahmadrasah yang menggunakan sistem baru (klasikal). Sekolah yang pertama kali menggunakan sistem baru tersebut adalah Sekolah Adabiyah di Padang yang didirikan oleh Syekh Abdullah Ahmad pada tahun 1909. 
Perkembangan dan Peningkatan mutu pendidikan Agama Islam di Minangkabau dimotivasi oleh Falsafah hidup masyarakat Minangkabau yang populer dengan Adat basandi syarak, syarak basandi Kitabullah, Syarak Mangato Adat Mamakai, selalu menjadi perbincangan mulai dari masyarakat kelompok terkecil sampai kepada tokoh masyarakat, dan para intelektual. Ulama dan tokoh adat merupakan dua sejoli yang tidak bisa dipisahkan melaksanakan falsafah hidup tersebut. Ulama dipandang sebagai orang yang tidak hanya mengetahui tentang halal dan haram, tetapi juga mengetahui tentang masalah dosa dan pahala. Di samping itu ulama juga dapat membimbing masyarakat agar menjalankan agama Islam dengan baik serta mendorong mereka untuk berbuat sesuai dengan falsafah hidup masyarakat Minangkabau (Duski Samad, 2003).

Di samping itu juga dibarengi oleh upaya Pernerintah dalam meningkatkan mutu madrasah. Kebijaksanaan Pemerintah dalam peningkatan mutu madrasah dijalankan atas dasar Surat Keputusan Betsama 3 Menteri, yakni Menteri Agama.. Menteri Pendidikan dan Kebudayaan. Menteri Dalam Negeri, masing-masing No. 6 Tahun 1975, No. 37 U11975 dan No. 36 Tahun 1975 tertanggal 24 Maret 1975.

Apabila kita pelajari SKB 3 Menteri, tersebut didalam konsideran terdapat anggapan dasar bahwa fungsi dan tugas madrasah masih belum dapat diharapkan secara penuh untuk mencapai tujuan pendidikan nasionaL Program pendidikan yang diselenggarakan masih belum dapat secara efektif ikut mencerdaskan kehidupan bangsa, sehingga masih menghasilkan adanya klasifikasi warganegara di dalam mernperoleh pekerjaan dan kehidupan yang layak bagi kemanusiaan.

Didalam SKB 3 Menteri tersebut madrasah diartikan sebagai Lembaga Pendidikan yang menjadikan mata pelajaran agama Islam sebagai mata pelajaran dasar yang diberikan Sekurangkurangnya 30\% disamping mata pelajaran umum (Ps. 1 ayat 1 ).

Peningkatan mutu pendidikan pada Madrasah bertujuan agar tingkat mata pelajaran umumnya sama dengan tingkat mata pelajaran umum di sekolah yang sederajat, sehingga dengan demikian, diharapkan agar dapat: 1. Ijazah madrasah dapat mempunyai nilai yang sama dengan ijazah sekolah umum yang sederajat; 2. Lulusan Madrasah dapat melanjutkan ke sekolah umum setingkat lebih atas; 3. Siswa madrasah dapat berpindah ke sekolah umum yang setingkat.

Guna memenuhi maksud di atas, dilakukan peningkatan-peningkatan di bidang: Kurikulum; Buku pelajaran, alat pendidikan lainnya dan sarana pendidikan pada umumnya; dan Pengajar.

Dengan terpenuhinya tiga hal di atas, maka madrasah akan: a). Memiliki eksistensi yang lebih mantap dan kuat, selaku lembaga pendidikan; b). Pengetahuan umumnya akan lebih baik; c). Fasilitas pisik dan peralatan akan lebih sempurna; d). Adanya civil effect terhadap ijazah madrasah.

Pada tahun 1976 baru bagi Madrasah Ibtidaiyah, Tsanawiyah dan Aliyah, masing-masing ditetapkan dengan SK 
Menteri Agama No. 73, No. 74 dan No. 75 tahun 1976 tertanggal 29 Desember 1976. Selanjutnya mengenai susunan organisasi dan tata kerja persekolahan, ditetapkan dèngan SK untuk tingkat Ibtidaiyah, Tsanawiyah dan Aliyah masing-masing No. 15, 16 dan 17 Tahun 1978. Keadaan madrasah negeri menjelang tahun 1978 sebelum diterbit kan SK. Menteri Agama tentang susunan organisasi dan tata kerja tersebut memiliki bentuk dan jenis yang bermacam-macam, yaitu: MIN, MTAIN, MAAIN, PGA 4 th, PGA 4 th, PPUPA, PHIN dan SPIAIN. Kemudian dilakukan penyederhanaan bentuk dan struktur persekolahan yang dituangkan ke dalam SK Menteri Agama Nomor: 15, 16, 17 tahun 1978, sehingga terjadi perobahan nama menjadi: MIN, MTsN dan MAN. PGA 4 tahun menjadi Tsanawiyah, PGA 6 tahun menjadi MAN. PPUPA, PHIN dan SPIAIN menjadi MAN.

\section{Mengenai madrasah swasta} didasarkan SK Menteri Agama Nomor: 5 Tahun 1977 yang pendirian pelaksanaannya dituangkan ke dalam Surat Keputusan Dirjen Bimasa Islam No. Kep/D/69/77. Dalam hubungan mi madrasah swasta diartikan sebagai Lembaga Pendidikan yang menjadikan mata pelajaran agama Islam sebagai mata pelajaran dasar yang diberikan Sekurangkurangnya 30\% disamping mata pelajaran umum dan diselenggarakan oleh organisasi, Yayasan, Badan atau perorangan sebagai pengurus atau peniliknya. Seperti halnya madrasah negeri, madrasah swasta juga memiliki 3 tingkatan yakni: Tbtidaiyah, Tsanawiyah dan Aliyah dengan masa belajar 3 tahun. Madrasah swasta mempunyai status Terdaftar dan disamakan. Madrasah terdaftar apabila telah mendaftarkan diri pada instansi Departemen Agama yang ditunjuk oleh Menteri Agama. Sedangkan dipersamakan mempunyai status fungsi dan kewajiban yang sama dengan madrasah negeri.

Madrasah dapat dipersamakan apabila memenuhi persyaratan antara lain memiliki tempat belajar, fasilitas guru yang mencukupi, menggunakan kurikulum Departemen Agama, menjalankan administrasi yang teratur dan untuk beberapa tahun berturut turüt menghasilkan lulusan ujian ngara dengan hasil baik. Prosedur untuk memperoleh status .dipérsamakan diatur dalam pasal 4 SK Dirjen No. KEP/D/69/77 dengan terlebih dahulu dilakukan oleh Seluruh team teknis selama' 6 han berturut-turut. Keputusan tentang Madrasah yang dipersamakan dilakukan oleh Dirjen Binbaga Islam.

Madrasah sebagai wadah pendidikan Calon Ulama. Pada tanggal 8 Juli 1985 di Jakarta pernah diselenggarakan silaturahmi pertemuan Pondok Pesantren dengan Majelis Ulama Indonesia: Dalam pertemuan tersebut Majelis Ulama Indonesia mengkoodinir adanya penurunan kwalitas dan kwantitas Uläma di Indonesia. Lebih jauh Bapak Menteri Agama mensinyalir bahwa ulama semakin langka. Mènangkap isyarat Bapak Menteri Agama tersebut, bila kita tannya kepada kondisi lembaga pendidikan Islam yang memproduk caloncalon ulama. Kemudian kita amati pula kwantitas nama sejak menjelang kemerdekaan sampai kurang lebih 4 dasawarsa akhir menunjukkan jumlah yang menurun.

Pada poriode perang kemerdekaan antara 1945-1950 Madrasah yang menjadi perkumpulan para ulama sekaligus menjadi markas.-markas 
perjuangan. Hal mi menyebabkan tidak sedikit ulama vang gugur. Akibat daripada itu madrasahpun menjadi tenlantar dan semakin tidak berfungsi sebagai leinbaga pendidikan calon ulama. Keadaan itu semakin bertambah terasa karena setelah banyak ulama yang mengaambil bahagian dalam menduduki badan-badan legislatif menjadi pegawai negeri dan swasta. Dampaknya adalah terhentinya usaha perkaderan ulama. Ulama di sini bukanlah hanya seorang yang disebut syekh/buya yang menguasai kitab-kitab feqih saja, tetapi ia memberikan penilaian bagaimana seharusnya. Ia juga berfungsi sebagai penguasa ilmu agama, pemimpin, pembimbing dan pelita ummat yang bertanggung jawáb atas kecerdasan. kesejahteraan, kesalamatan dan kebahagiaan ummat dalam melaksanakan ketentuan-ketentuan agama.

Langkah-langkah kebijaksanaan yang telah ditempuh dan setelah diadakan penelitian dan penilaian terhadap pelaksanaan pendidikan pada Madrasah yang telah berjalan selama mi, pemerintah menganggap perlu untuk melakukan perbaikan dan penyempurnaan pelaksanaan pendidikan pada. Lembaga-lembaga pendidikan agama, sehingga diharapkan dapat menghasilkan siswa yang memiliki bekal pengetahuan dasar dalam iimu-ilmu agama dan bahasa Arab yang diperlukan untuk melanjutkan pendidikan ke IAIN dan atau dapat bekerja di masyarakat dalam bidang pelayanan keagamaan. Sehubungan dengan itu, telah dikeluarkan Keputusan Menteni Agama RI Nomor: 73 Tahun 1987 tanggal 30 April 1987 tentang Penyelenggaraan Madrasah Aliyah Program Khusus (MAPK).
Dengan MAPK tersebut, dimaksudkan agar dapat mengarahkan anak didik untuk menjadi muslim yang bertaqwa, manusia pembangunan dan menjadi warga negara Indonesia yang berpancasila dan UUD-45 serta membekali pengetahuan dasar dalam ilmu ilmu Agama dan berkemampuan berbahasa Arab sehingga memiliki kemampuan di masyarakat dalam bidang keagamaan.

Dengan adanya MAPK bukan berarti hapusnya Madrasah Aliyah Negeri yang sekarang tetapi tetap berjalan dengan berpedoman pada SK.B tiga Menteri sebagaimana yang telah dijelaskan di atas.

Kemudian lembaga pendidikan Islam yang ada di Minangkabau tidak dapat tidak harus mengikuti kebijakan pemerintah dalam hal ini Menteri Agama. Melihat kepada fase-fase perkembangan di atas, maka lembaga pendidikan di Minangkabau juga mengalami perobahan yang pada awalnya surau kemudian berganti mama dengan Madrasah Tarbiyah Islamiyah, Perguruan Thawalib, Diniyah, Ma'had Islamy untuk swasta, bahkan sampai dengan fase Orde Baru madrasah swasta sudah banyak yang berganti nama dengan Pondok Pesantren.

Keberadaan madrasah/pesantren sebagai sebuah lembaga yang ikut berperan dalam mendidik dan mencerdaskan anak bangsa kurang mendapat apresiasi dari pemerintah. Terutama pada saat para pemegang kebijakan negara (dalam bidang pendidikan) menggunakan paradigma "developmentalis". Paradigma ini adalah wujud dari buah modernisme dan 
kapitalisme. Karena itu madrasah dianggap sebagai komunitas yang terbelakang, tidak modern, tradisional, hingga kemudian dikesampingkan.

Ketika orde baru berkuasa, dimunculkan kebijakan "modernisasi pesantren" yang berorientasi mengubah tradisionalitas dan ketertinggalan pesantren agar seirama dengan paradigma pembangunan negara. Dalam kenyataannya, selain memporakporandakan konstruksi fisik dan program pengembangan pesantren, proyek ini juga merusak relung-relung sistem pendidikannya. Tawaran yang disodorkan pada waktu itu adalah masuknya pendidikan sekolah dan madrasah dengan suatu jaminan fasilitas tertentu.

Di lain pihak lembaga pendidikan Agama Islam di Minangkabau juga mengalami perobahan seperti Pendidikan Guru Agama (PGA)- sekarang tidak ada lagi, Madrasah Tsanawiyah Negeri, Madrasah Aliyah Negeri, Sekolah Persiapan IAIN- sudah dihapuskan-, untuk tingkatan pertama dan menengah (Marwan, Sarijo, 2011), sedangkan untuk Perguruan Tinggi Islam di Minangkabau pertama didirikan oleh Mahmud Yunus pada tanggal 9 Desember 1940.

Sejak 1945-1959 sekolah-sekolah pemerintah resmi dimasukkan, serta guru-guru agama pun ditetapkan dan mendapat gaji. Hasil ini didapat diantaranya karena perjuangan Mahmud Yunus yang pada waktu itu menjabat sebagai pemeriksa agama pada kantor pengajaran di Minangkabau. Dari sanalah, pendidikan Islam dikembangkan dari pendidikan dasar sampai perguruan tinggi.

Sampai dengan fase Orde Baru di samping IAIN juga ditingkatkan menjadi Pasca Sarjana baik program Strata Dua (S2) maupun Strata tiga (S3) dengan tetap memakai nama IAIN Imam Bonjol Padang. Kemudian disamping IAIN juga berdiri dua buah Perguruan Tinggi Negeri di bawah pengelolaan pemerintah, seperti Sekolah Tinggi Agama Islam Bukittinggi, Sekolah Tinggi Agama Islam Negeri Batusangkar bahkan pada era reformasi kemajuan lebih ditingkatkan lagi sehingga tahun 2014 dengan Peraturan Presiden Nomor 181/2014 tanggal 18 Desember 2014 Sekolah Tinggi Agama Islam Negeri Bukittinggi berubah menjadi IAIN Bukitinggi, disusul kemudian dengan Peraturan Presiden Nomor 147/2015 Sekolah tinggi Agama Islam Batusangkar berobah menjadi IAIN Batusangkar, dan terakhir dengan Peraturan Presiden Nomor 35 tahun 2017 IAIN Imam Bonjol Padang beralih status menjadi Universitas Islam Negeri Imam Bonjol Padang yang mana sebelum alih status ini juga menjadi perdebatan hangat di tengah tengah masyarakat.

Sedangkan untuk swasta tumbuh dan berkembang dengan pesat, seperti Universitas Muhammadiyah dengan Pendidikan Agama Islamnya, Universitas Ahlussunnah dengan Jurusan Pendidikan Agama Islam, Sekolah Tinggi Agama Islam Yayasan Tarbiyah Islamiyah Padang (STAI YASTIS) dengan Jurusan Pendidikan Agama Islam dan sekolah tinggi lainnya yang dikelola oleh sebuah yayasan yang terdapat di beberapa kabupaten dan kota di Sumatera Barat. Semua perguruan tinggi swasta tersebut berada di bawah naungan/binaan Kopertais Wilayah VI Sumatera Barat yang berjumlah 21 Perguruan Tinggi Agama Islam Swasta. Dokumentasi Kopertais Wilayah VI Sumatera Barat 
tahun 2017 dengan rincian di Kota Padang terdapat 4 buah, Kota Pariaman 1 buah, Kabupaten Tanah Datar 2 buah, Kota Padang Panjang 2 buah, Kota Bukittinggi 1 buah, Pasaman Timur 1 buah, Pasaman Barat 2 buah, Kabupaten Sijunjung 1 buah, Kota Solok 1 buah, Kota Payakumbuh 2 buah, Kabupaten Pesisir Selatan 3 buah, terakhir Kabupaten Dharmasraya terdapat 1 buah Perguruan Tinggi Swasta.

Dengan demikian Sekolah Tinggi Agam Islam Negeri (STAIN) di Minangkabau menjadi kosong, boleh jadi kekosongan ini akan diisi oleh salah satu Perguruan Tinggi Swasta yang 21 buah, tergantung kepada kemauan dan persyaratan yang harus dipenuhi oleh masing masing PTAIS sesuai dengan aturan yang berlaku.

Dalam pengelolaan Perguruan Tinggi Swasta dengan jumlah 21 PTAIS seyogyanya dikelola oleh sebuah Kopertais bertugas melakukan pengawasan, pengendalian dan pembinaan terhadap Perguruan Tinggi Swasta di Sumatera Barat yang merupakan satu lembaga Pemerintah dibawah Dirjen Pendidikan Tinggi Islam dan mempunyai struktur tersendiri di luar Universitas Islam Negeri Imam Bonjol Padang sebagaimana yang telah dilaksanakan oleh Kopertis Wilayah X Sumbar.

\section{PENUTUP}

Hasil Dari paparan di atas dapat disimpulkan bahwa dalam perjalanan sejarah menunjukkan bahwa Pendidikan Islam di Minangkabau pada awalnya berasal dari surau yang didirikan oleh masyarakat dengan sistem yang sangat sederhana. Kemudian seiring dengan dinamika perkembangan zaman secara berangsur angsur terjadi perobahan yang signifikan baik dari segi kualitas maupun kuantitas terutama lembaga pendidikan yang dikelola oleh pemerintah, sedangkan Lembaga Pendidikan Islam yang dikelola oleh masyarakat/Swasta dari segi kuantitas menunjukkan peningkatan yang begitu cepat, sedangkan dari segi kualitas masih kurang mendapat perhatian yang serius dari pemerintah.

\section{REFERENSI}

Ar-Rasuly, Baharuddin, Sejarah Lengkap Persatuan Tarbiyah Islamiyah, Candung, 1979.

Ar-Rasuli, Sulaiman, Syekh, Pertalian Adat dan Syara' (Alih bahasa oleh Drs. Hamdan Izmy), Jakarta, Ciputat Press, 2003

Aboe Nain, Sjafnir, Tuanku Imam Bonjol, Sejarah Intelektual Islam di Minangkabau 1784-1832, Padang, Esa Padang, 1988.

Arifin, H.M. Filsafat Pendidikan Islam, Jakarta: Bumi Aksara, 1993.

--, Kapita Selekta Pendidikan, Islam dan Umum, Jakarta: Bina Aksara, 1991

Ali, Mohammad Daud, Lembaga-Lembaga Pendidikan Islam di Indonesia, Jakarta; Raja Grafindo Persada, 1995

Asrohah, Harun, Sejarah Pendidikan Islam, Jakarta: Logos, 1999

Azra, Azyumardi, Jaringan Ulama Timur Tengah dan Kepulauan Nusantara Abad XVII \& XVIII, Jakarta: Presada Media,2004 
, Pendidikan Islam; Tradisi

dan Modernisasi Menuju Millenkium

Baru, Jakarta: Logos, 1999

Amir, Mafri, Corak Pers Islam Masa Lampau:Studi Kasus Majalah Soeloeh Melajoe(1913-1915), Program Pelatihan Tenaga Edukatif IAIN Imam Bonjol Padang Tahun 1998/1999.

Chairusdi, Sejarah Perjuangan dan Kiprah PERTI Dalam Dunia Pendidikan Islam di Minangkabau, Cet. I, IAIN IB Press, 2001.

Dhofier, Zamkhsyari, Tradisi Pesantren; Studi Tentang Pandangan Hidup Kiyai, Jakarta: LP3ES, 1999

Daradjat, Zakiah, et-al, Ilmu Pendidikan Islam, Jakarta, Bumi Aksara, 1996 Pembinaan Mental, Jakarta: Bulan Bintang, 1982

Daya, Baharuddin, Gerakan Pembahartuan Pemikiran Islam Kasus Sumatera Thawalib, Yogyakarta, Tiara Wacana, 1990.

Direktorat Jenderal Pendidikan Islam Departemen Agama RI, Undangundang dan Peraturan Pemerintah RI tentang Pendidikan, tahun 2006.

Enung K Rukiati dkk, Sejarah Pendidikan Islam Di Indonesia, (Bandung: Pustaka Setia, 2004)

Edwar (ed), Riwayat Hidup dan Perjuangan 20 Ulama Besar Sumatera Barat, Padang: Islamic Center Sumatera Barat, 1981
Hasil Seminar, Masuknya Islam ke Indonesia, tgl.17-20 Maret 1963, di Medan Sumatera Utara dan Langsa Aceh Timur, tgl.25-30 September 1980.

Langgulung, Hasan, Azas-Azas Pendidikan Islam, Jakarta:Pustaka al-Husna, 1998

Jurnal Pemikiran dan Kebudayaan Islam, Empirisme, Vol.14 No.2 Juli 2005

Jaya, Tamar, Riwayat Hidup Orang-orang Besar Tanah Air, Jakarta, Pusaka Indonesia, 1965) cet.IV

Koto, Alaidin, Pemikiran Politik PERTI, Persatuan Tarbiyah Islamiyah (1945-1970), PT. Nimas Multima, Jakarta, cet.I.

Kahin, Audrey, Penterjemah Drs.Azmi dkk., Dari Pemberontakan ke Integrasi, Smatera Barat dan Politik Indonesia 1926-1998, Jakarta, Yayasan Obor Indonesia, 2005

Khatib, Syamsul Bahri, Corak Pemikiran Keagamaan Sesudah Kemerdekaan RI di Sumbar, Hasil Penelitian sebagai Dosen IAIN Imam Bonjol Padang tahun 1985.

Kamal, Tamrin, Wanita Penguasa Pada Masyarakat Matrilineal dan Peranannya dalam Keluarga dan Masyarakat Luas (Kasus Penguasa Konmfeksi di Kec.IV Abgkat Candung, Sumatera Barat),, Bogor, Tesis S-2 IPB,1991

Latief, M.Sanusi, Gerakan Kaum Tua di Minangkabau, Disertasi S3, IAIN Syarif Hidayatullah Jakarta,

Mustafa, H.A, dkk, Sejarah Pendidikan Islam di Indonesia, Bandung: CV. Pustaka Setia, 1999 
Mulyani, Surau dan Pembaharuan Pendidikan Islam di Minangkabau, Padang, IAIN IB Press,1999

Majalah Ilmiah Pengembangan Ilmu dan Pemikiran Keagamaan, Tajdid, No.4, Vol.2 tahun 1999

Ma'arif, A. Syafi'i Islam; Kekuatan Doktrin dan Kegamangan Umat, Yogyakarta: Pustaka Pelajar, 1997

Mastuhu, Dinamika Sistem Pendidikan Pesantren, Jakarta: INIS, 1994

Nata, Abuddin, (ed), Sejarah Pertumbuhan dan Perkembangan Lembaga-lembaga Pendidikan Islam di Indonesia, Jakarta; Gramedia Widiasarana Indonesia, 2001

Noer, Deliar, Gerakan Moderen Islam di Indonesia, (Jakarta:LP3ES, 1980), hal.38-47

Rahardjo, M.Dawam (ed.), Pergulatan Dunia Pesantren; Membangun dari bawah, Jakarta: P3M,tth

(ed) Pesantren dan Pembaharuan, Jakarta; LP3ES, 1995
Sarijo, Marwan, Pendidikan Islam dari Masa ke Masa, Tinjauan Kebijakan Publik Terhadap Pendidikan Islam di Indonesia, (Bogor, Yayasan Ngali Aksara dari Al-Manar, 2011, Cet.II (edisi Revisi).

Soejoeti, Zarkowi, Meningkatkan Mutu Pendidikan pada Madrasah dalam rangka Pendidkan Calon Ulama, Mimbar Ulama, No.138 tahun 1989.

Salmadanis dan Duski Shamad, Adat Basandi Syara', Nilai dan Aplikasinya Menuju Kembali ke Nagari dan Surau, Jakarta, Kartika Insan Lestari, 2003

Yunus, Mahmud, Sejarah Pendidikan Islam di Indonesia, Jakarta, Hida Karya Agung, 1996.

Yasir, Modernisasi Pesantren, Kritik Nurcholis Madjid Terhadap Pendidikan Islam Tradisional, Jakarta, Ciputat Press, tahun 2002

Zed, Mestika, dkk., Sumatera Barat di Pangoung Sejarah 1945-1995, Jakarta, Pustaka Sinar Harapan,1998 
104 || Turast: Jurnal Penelitian dan Pengabdian Vol. 6, No. 1, Januari-Juli 2018 
